\title{
EFFECT OF INTRAOCULAR LENS FIXATION ON ACUTE INTRAOCULAR PRESSURE RISE AFTER NEODYMIUM-YAG LASER CAPSULOTOMY
}

\author{
N. ANAND, D. M. TOLE and A. J. MORRELL \\ Leeds
}

\begin{abstract}
SUMMARY
Neodymium-YAG laser posterior capsulotomy is associated in some cases with an acute rise in the intraocular pressure (IOP), possibly caused by blockage of the trabecular meshwork by debris. To test the hypothesis that the IOP rise is preventable if fixation of the intraocular lens (IOL) in the capsular bag is ensured, we conducted a study comparing IOP changes at 1, 2,3 and 24 hours after Nd:YAG capsulotomy between eyes with capsular bag-fixated, one haptic in the bag (haptic in/out) and ciliary sulcus-fixated IOLs. Analysis of variance for repeated measures showed that after capsulotomy there were significant increases in IOP from baseline $(p<0.05)$ in both the sulcus-fixated $(1,2$ and 3 hours) and haptic in/out groups ( 2 and 3 hours), while IOPs in the bag-fixated group did not show any significant increase. The increases in IOP in the sulcusfixated group at 1, 2 and 3 hours after capsulotomy were significantly higher than the IOP changes at the corresponding periods in the other two groups (Kruskal-Wallis test, $p<0.01)$. The mean maximum IOP rise in the sulcus-fixated group $(11.33 \pm 7.85 \mathrm{mmHg})$ was significantly higher than that in the haptic in/out group $(3.89 \pm 7.14 \mathrm{mmHg})$ and the bag-fixated group $(1.10 \pm$ $2.71 \mathrm{mmHg}$ ), while there was no difference between the latter two groups. In $57.5 \%$ of the sulcus-fixated group, $5 \%$ of the haptic in/out group and none of the eyes of the bag-fixated group the IOP rise was more than 10 mmHg. A significantly larger proportion of sulcusfixated eyes had anterior chamber cells and capsular debris after capsulotomy $\left(\chi^{2}\right.$ test, $\left.p<0.001\right)$. In the haptic in/out group significant correlation $(-0.56, p=$ 0.009 ) between IOP rise at 1 hour and the percentage enclosure of the IOL by the anterior capsule was demonstrated. There was no significant difference in maximum IOP rise between glaucomatous and nonglaucomatous eyes (Mann-Whitney $U$-test, $p=0.49$ ).
\end{abstract}

From: St James's University Hospital, Leeds, UK.

Correspondence to: Mr Nitin Anand, MD (Ophth), FRCSEd (Ophth), 28 Ambleside Gardens, Wembley, Middlesex HA9 8TL, UK.
Acute, short-term elevations in intraocular pressure (IOP) following neodymium-YAG (Nd:YAG) laser posterior capsulotomies are well documented. ${ }^{1-5}$ The mechanism proposed is blockage of the trabecular meshwork by capsular and inflammatory debris. ${ }^{1}$ Shock-wave-induced damage to the meshwork appears to contribute to the IOP elevation. ${ }^{2}$ This laser-induced pressure spike is reported to be less severe in pseudophakic eyes than in aphakic eyes, ${ }^{3}$ the proposed reason being that the intraocular lens (IOL) acts as a barrier to the anterior migration of capsular debris. Gimbel et al. ${ }^{6}$ demonstrated that IOL fixation plays an important role in determining the amplitude of the pressure spikes. Eyes with bagfixated IOLs did not have any clinically significant pressure spikes, and it was hypothesised that bagfixated IOLs provide a more effective barrier to capsular debris and may have a dampening effect on the YAG-induced pressure wave and consequent trabeculitis.

Most studies on acute IOP elevation following Nd:YAG laser capsulotomies were undertaken before the advent of circumlinear continuous capsulorrhexis (CCC). The growing popularity of CCC and small-incision cataract surgery has made it possible to ensure in-the-bag IOL fixation. The aim of this study was to determine the relationship, if any, of IOL fixation to acute IOP elevation following $\mathrm{Nd}$ :YAG laser posterior capsulotomy.

\section{METHODS}

Patients scheduled for Nd:YAG laser posterior capsulotomies at the Eye Clinic, St James's University Hospital, Leeds, between September 1994 and April 1995 were entered into the study. Informed consent was obtained and the patient data entered on specially designed forms. Three patients were scheduled for bilateral capsulotomies and only their right eye was included in the study. All laser procedures were carried out by two of the authors (N.A. and D.M.T.). All the pressure 
measurements in each patient were recorded by the same observer.

Pre-operative visual acuity and IOP were recorded. The position (fixation) of the IOL was recorded after dilatation of the pupil. In eyes which had had a CCC, if the anterior capsulotomy edge was visible anterior to the IOL optic throughout its circumference it was assumed that the IOL was in the bag. Otherwise the IOL haptics were directly visualised with a Goldman three-mirror lens. Eyes were categorised into three groups according to the fixation of the IOL: bag-fixated, one haptic in the bag (haptic in/out) or both haptics sulcus-fixated. The percentage enclosure of the IOL haptic by the anterior capsule was noted in all cases and graded as follows: grade 1, $0-25 \%$ enclosure; grade 2, $25-50 \%$ enclosure; grade 3, 50-75\% enclosure; grade $4,75-100 \%$ enclosure. IOPs were measured at 1,2, 3 and 24 hours after the capsulotomy. All eyes were assessed for anterior chamber activity, which was deemed to be present if pigment cells and/or capsular debris were seen there. If the IOP rose more than $10 \mathrm{mmHg}$ at any time, patients were administered oral acetazolamide. Patients with glaucoma were treated if the IOP rose beyond $30 \mathrm{mmHg}$ at any time. Topical steroid drops were prescribed to patients whose eyes had severe post-operative iritis.

Statistical analyses of the data were undertaken using the Statistical Package for Social Sciences (SPSS) software. IOP changes after laser in each group were analysed by multivariate analysis of variance for repeated measures (MANOVA). IOP measurements were transformed logarithmically to satisfy the requirements for parametric analyses. Differences in pressures within groups over time were evaluated as pairs using Tukey's HSD (honestly significant difference) test at $p<0.05$ levels. Univariate analyses of IOP changes at 1, 2, 3 and 24 hours and the maximum IOP rise at any time between
Table I. Patient characteristics

\begin{tabular}{lccc}
\hline & \multicolumn{3}{c}{ IOL fixation } \\
\cline { 2 - 4 } & $\begin{array}{c}\text { Bag- } \\
\text { fixated }\end{array}$ & $\begin{array}{c}\text { Haptic } \\
\text { in/out }\end{array}$ & $\begin{array}{c}\text { Sulcus- } \\
\text { fixated }\end{array}$ \\
\hline No. of patients & & & \\
Sex (M/F) & 43 & 21 & 28 \\
Average age (years) & $18 / 35$ & $3 / 18$ & $13 / 15$ \\
Interval (years) $^{b}$ & 76.22 & 75.69 & 71.28 \\
Total laser energy (mJ) $^{\prime}$ & 1.9 & 2.43 & 2.76 \\
\hline
\end{tabular}

${ }^{a}$ Excluded from analyses: 2 patients with aphakia, 1 with undetermined IOL fixation and 19 with glaucoma.

${ }^{b}$ Interval between cataract surgery and laser capsulotomy.

groups was compared by the Kruskal-Wallis oneway analysis of variance (ANOVA). The maximum difference in the IOP rise between glaucoma and non-glaucoma patients was evaluated by the MannWhitney $U$-test. Categorical variables were assessed by the $\chi^{2}$ test and correlations by Spearman's correlation coefficient.

\section{RESULTS}

The total number of patients (and eyes) entered in the study was 114 . Nineteen eyes with glaucoma or ocular hypertension were analysed separately. Two aphakic eyes and 1 eye with undetermined IOL fixation were excluded from the analyses. There were 43 eyes in the bag-fixated group, 21 in the haptic in/ out group and 28 in the sulcus-fixated group (Table I). There was no significant difference in age between patients in the three groups. There were a significantly larger number of females in the haptic in/out group but this was not considered to affect the outcome of the study. There was no significant difference in the interval between cataract extraction and capsulotomy between the groups (ANOVA, $p=$ $0.199)$. There was a significant difference in the average energy levels required for capsulotomy between the groups (ANOVA, $p=0.006$ ), the sulcus-fixated group requiring higher total energy

Table II. Intraocular pressure profile after capsulotomy

\begin{tabular}{|c|c|c|c|c|c|c|}
\hline & \multicolumn{2}{|c|}{ Bag-fixated IOL } & \multicolumn{2}{|c|}{ Haptic in/out IOL } & \multicolumn{2}{|c|}{ Sulcus-fixated IOL } \\
\hline & IOP (mmHg) & Change $(\mathrm{mmHg})$ & IOP $(\mathrm{mmHg})$ & Change $(\mathrm{mmHg})$ & IOP $(\mathrm{mmHg})$ & Change $(\mathrm{mmHg})$ \\
\hline Pre-YAG & $\begin{array}{c}15.23(2.50) \\
n=43\end{array}$ & & $\begin{array}{c}16.52(2.53) \\
n=21\end{array}$ & & $\begin{array}{c}18.00(3.83) \\
n=28\end{array}$ & \\
\hline Post-YAG & & & & & & \\
\hline 1 hour & $\begin{array}{c}14.90(2.5) \\
n=43\end{array}$ & $-0.27(2.40)$ & $\begin{array}{c}18.47(5.99) \\
n=21\end{array}$ & $1.95(5.01)$ & $\begin{array}{c}27.10(9.42) \\
n=28\end{array}$ & *9.10 (7.82) \\
\hline 2 hours & $\begin{array}{c}15.81(3.2) \\
n=41\end{array}$ & $0.58(2.96)$ & $\begin{array}{c}19.66(6.41) \\
n=17\end{array}$ & *3.11 (5.09) & $\begin{array}{c}28.03(9.75) \\
n=27\end{array}$ & *10.61 (8.03) \\
\hline 3 hours & $\begin{array}{c}15.65(2.9) \\
n=37\end{array}$ & $0.35(2.01)$ & $\begin{array}{c}19.81(4.64) \\
n=15\end{array}$ & $* 3.00(3.00)$ & $\begin{array}{c}28.42(8.13) \\
n=26\end{array}$ & *10.50 (6.68) \\
\hline 24 hours & $\begin{array}{c}14.99(2.37) \\
n=34\end{array}$ & $-0.35(1.64)$ & $\begin{array}{c}17.13(3.24) \\
n=15\end{array}$ & $0.30(1.58)$ & $\begin{array}{c}19.52(3.67) \\
n=25\end{array}$ & $1.56(2.66)$ \\
\hline Max. IOP rise & & $1.10(2.71)$ & & $3.89(7.14)$ & & $11.33(7.85)$ \\
\hline
\end{tabular}

*Indicates a significant change $(p<0.5)$ from baseline (pre-YAG capsulotomy).

$p$ between groups: no significant difference in IOP $(p>0.05)$ at $1,2,3$ and 24 hours between bag-fixated and haptic in/out groups.

Significant difference $(p<0.05)$ at 1,2 and 3 hours between sulcus-fixated and both bag-fixated and haptic in/out groups, but no difference at 24 hours. 


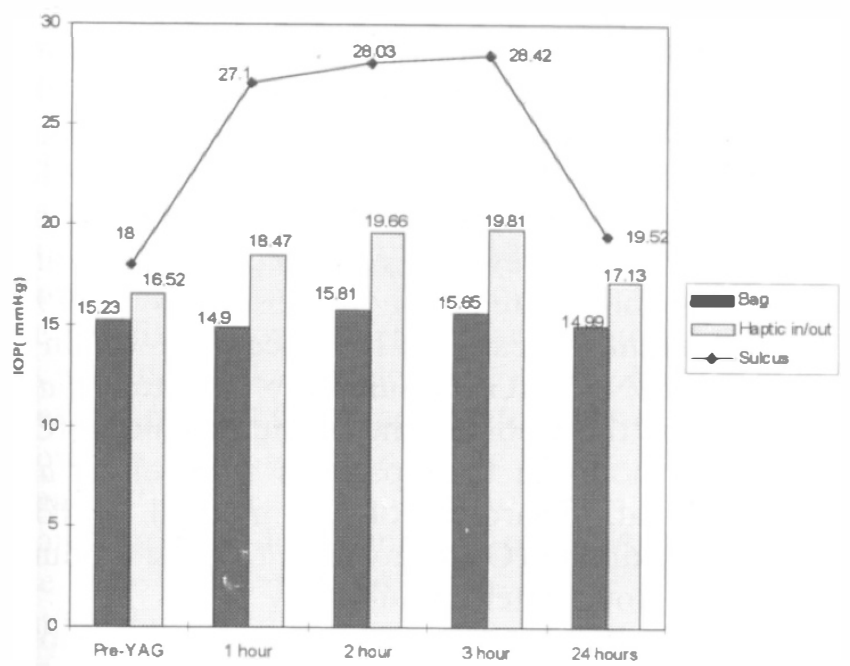

Fig. 1. Intraocular pressure changes after Nd:YAG laser capsulotomy, related to the method of IOL fixation.

levels for adequate capsulotomies. This confirmed our clinical impression that these eyes had denser capsular opacification. The correlation between the percentage of the IOL circumference covered with anterior capsule and the IOP rise at 1 hour in the bag-fixated group was weak and not statistically significant (Spearman's correlation coefficient -0.22 , $p=0.128)$. In the haptic in/out group this correlation was significant at 1 hour $(-0.56, p=0.009)$.

Multivariate analysis for repeated measures (MANOVA) showed a significant change in IOP over the period studied, i.e. the 24 hours following Nd:YAG capsulotomy $(p<0.001)$. In the bag-fixated group there was no significant change in IOP from the baseline (pre-YAG capsulotomy) pressure of $15.23 \pm 2.5$ $\mathrm{mmHg}$. The mean IOP in the haptic in/out group rose from a baseline value of $16.52 \pm 2.53 \mathrm{mmHg}$ to $18.47 \pm 5.99 \mathrm{mmHg}$ in the first hour, peaked in the third hour at $19.81 \pm 4.64 \mathrm{mmHg}$ and returned to baseline levels of $17.13 \pm 3.24 \mathrm{mmHg}$ the next day. The sulcus-fixated group exhibited the greatest change in IOP. From the pre-capsulotomy mean value of $18.00 \pm 3.83 \mathrm{mmHg}$ the IOP rose to 27.10 $\pm 9.42 \mathrm{mmHg}$ at 1 hour, increasing slightly to $28.42 \pm$ $8.13 \mathrm{mmHg}$ at 3 hours. The next day, mean IOPs had fallen to $19.52 \pm 3.67 \mathrm{mmHg}$ and were not significantly higher than baseline levels (Table II, Fig. 1).
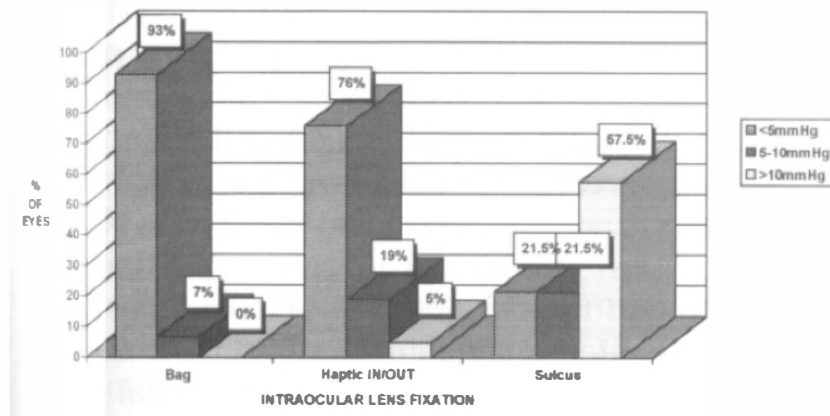

Fig. 2. Intraocular pressure rise after $N d: Y A G$ laser capsulotomy, related to the method of IOL fixation.
MANOVA and other multivariate tests of 'between-subject effects' demonstrated a significant effect of IOL fixation on IOP (effect $p<0.001$; observed power at the 0.05 level $=1.00)$. There was no difference in the baseline pressures or the pressures at 24 hours between the groups $(p>0.05)$. There was a significant difference in the maximum pressure rise at any time between the groups as compared by the Kruskal-Wallis test $(p<0.001)$. Comparisons of specific groups using the KruskalWallis test (Dunn's method at $p<0.05$ levels) showed that the maximum rise in IOP in the sulcus-fixated group was significantly higher than that in the other two groups. There was, however, no significant difference in the maximum pressure rise between the bag-fixated and haptic in/out groups. The sulcusfixated group had significantly higher pressures than the other two groups $(p<0.05)$ at 1,2 and 3 hours after capsulotomy. There was no significant difference in the pressures recorded at 1,2 and 3 hours post-capsulotomy between the bag-fixated and haptic in/out groups.

Eyes in the bag-fixated group did not show acute IOP spikes. Only 3 eyes $(7 \%)$ had a pressure rise of between 5 and $10 \mathrm{mmHg}$ and none had a rise of more than $10 \mathrm{mmHg}$. At no time did the IOP exceed 30 $\mathrm{mmHg}$ in any of the bag-fixated eyes. Four eyes $(19 \%)$ in the haptic in/out group had a pressure rise of between 5 and $10 \mathrm{mmHg}$ and only 1 eye $(5 \%)$ had a pressure rise of more than $10 \mathrm{mmHg}$. Eyes in the sulcus-fixated group had rather dramatic rises in IOP and many of them required treatment. Six eyes $(21.5 \%)$ had a pressure rise of between 5 and 10 $\mathrm{mmHg}$ and $16(57.5 \%)$ had a pressure rise of more than $10 \mathrm{mmHg}$ (Fig. 2). The results of the 19 eyes with either glaucoma or ocular hypertension are shown in Table III. None of the eyes with a bagfixated IOL had a clinically significant pressure rise, whereas in the haptic in/out and the sulcus-fixated groups, 3 eyes each had acute pressure spikes which required treatment. A comparison of the maximum

Table III. Intraocular pressure changes after capsulotomy in eyes with glaucoma

\begin{tabular}{lccc}
\hline & \multicolumn{3}{c}{ IOL fixation } \\
\cline { 2 - 4 } & $\begin{array}{c}\text { Bag- } \\
\text { fixated } \\
(n=6)\end{array}$ & $\begin{array}{l}\text { Haptic } \\
\text { in/out } \\
(n=7)\end{array}$ & $\begin{array}{c}\text { Sulcus- } \\
\text { fixated } \\
(n=6)\end{array}$ \\
\hline Pre-YAG & $17.6(2.7)$ & $18.5(2.3)$ & $22.8(2.7)$ \\
Post-YAG & & & \\
$\quad 1$ hour & $18.2(2.8)$ & $25.3(6.8)$ & $31.4(4.2)$ \\
2 hours & $17.7(2.3)$ & $25.8(7.2)$ & $31.4(4.7)$ \\
3 hours & $17.8(2.5)$ & $22.3(4.8)$ & $28.4(3.8)$ \\
4 hours & $17.8(2.8)$ & $16.8(1.7)$ & $19.8(1.42)$ \\
IOP rise > 5 mmHg: no. (\%) & 0 & $3(43 \%)$ & $3(60 \%)$ \\
AC reaction: no. of eyes (\%) & $2(33 \%)$ & $4(57 \%)$ & $4(67 \%)$ \\
\hline
\end{tabular}

$n$, number of eyes; $\mathrm{AC}$, anterior chamber.

Values are the mean IOP in $\mathrm{mmHg}$; numbers in parentheses indicate the standard deviation. 


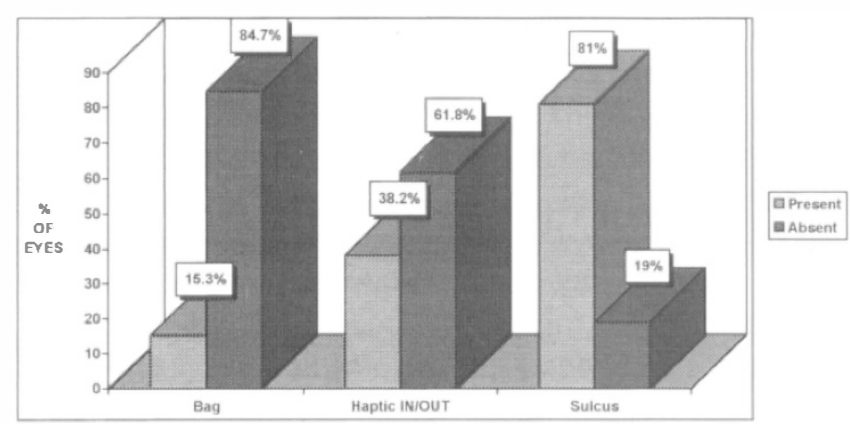

Fig. 3. Anterior chamber inflammation after $N d: Y A G$ capsulotomy, related to the method of IOL fixation.

IOP rise at any time between glaucomatous and nonglaucomatous eyes revealed no significant difference (Mann-Whitney $U$-test, $p=0.49$ ). There was no significant difference in the proportion of cases showing a pressure rise of more than $5 \mathrm{mmHg}\left(\chi^{2}\right.$ test, $p=0.858)$ between glaucomatous and nonglaucomatous eyes.

Anterior chamber cells and capsular debris were observed in $7(15.3 \%)$ eyes of the bag-fixated group, $8(38.2 \%)$ eyes of the haptic in/out group and 22 $(81 \%)$ eyes of the sulcus-fixated group (Fig. 3). These differences were highly significant $\left(\chi^{2}\right.$ test, $p$ $<0.01$ ). Elevation of IOP after capsulotomy appeared to be closely associated with anterior chamber activity in the sulcus-fixated group only. The presence of anterior chamber activity was associated with an IOP rise of more than $5 \mathrm{mmHg}$ in 3 eyes (of 7 with an anterior chamber reaction; $42.8 \%$ ) in the bag-fixated group, 3 eyes (of $8 ; 37.5 \%$ ) in the haptic in/out group and 18 eyes (of $22 ; 81.8 \%$ ) in the sulcusfixated group.

\section{DISCUSSION}

Transient IOP elevations following Nd:YAG laser capsulotomy appear to be associated with the type of IOL fixation. In this study, eyes with IOLs fixed in the bag did not have an acute pressure rise. In contrast a large proportion $(57.5 \%)$ of eyes with sulcus-fixated lenses had rather dramatic pressure spikes which necessitated immediate treatment. A smaller number of eyes with one IOL haptic in the bag and the other in the ciliary sulcus had pressure rises, with only $1(5 \%)$ eye requiring treatment for a pressure rise of more than $10 \mathrm{mmHg}$. The mean IOP rise at 1,2 and 3 hours after capsulotomy in this haptic in/out group did not differ significantly from the corresponding pressure change in the bag-fixated group. The sulcus-fixated IOL eyes, however, had significantly higher mean IOP elevations than the other two groups.

Higher mean energy levels were needed for capsulotomy in eyes with sulcus-fixated lenses. Sulcus-fixated IOLs are associated with early central posterior capsular fibrosis (ECPCF) which requires significantly higher energy levels than do Elschnig pearls. ${ }^{7}$ However, with the exception of a few early reports, a statistical association between the IOP rise and the laser energy level used for capsulotomy remains to be demonstrated. ${ }^{1-4}$ Our reason for measuring pressures for 3 hours after capsulotomy was based on previous reports. Slomovic and Parrish $^{5}$ demonstrated that in most eyes $(81.7 \%)$ the maximum increase in IOP occurred within 3 hours after Nd:YAG capsulotomy. Richter et al. ${ }^{1}$ showed that the median time to the maximum IOP rise was 3 hours in their patients. Gimbel et al. ${ }^{4}$ reported that, regardless of the method of IOL fixation, maximum IOP rise was in the first 3 hours, falling at 6 hours after capsulotomy.

It is difficult to compare our results with previous reports. A review of the literature revealed only two studies which reported IOP rises following Nd:YAG capsulotomy in relation to IOL fixation. Gimbel et al. ${ }^{4}$ reported no significant rise in IOP at 1, 2, 3 and 6 hours after capsulotomy in bag-fixated cases and a significant IOP rise in the combined sulcus-fixated and haptic in/out group at 1,2 and 3 hours but not at 6 hours. The combined group had significantly higher IOPs than the bag-fixated group in the first 3 hours, the mean pressure rises being $4.9 \pm 5.3 \mathrm{mmHg}$ in the first hour, $6.9 \pm 4.3 \mathrm{mmHg}$ in the second hour and $7.83 \pm 8.3 \mathrm{mmHg}$ in the third hour after capsulotomy. This compares well with the equivalent values of $6.0 \pm 7.6 \mathrm{mmHg}, 7.5 \pm 7.7 \mathrm{mmHg}$ and $7.8 \pm 6.7$ $\mathrm{mmHg}$ in the present study. It is evident from our results that the IOP changes after capsulotomy in the haptic in/out group are not significantly different from those of the bag-fixated group, and it would be inappropriate to place them in the same category as those of the sulcus-fixated group. In another study, Altamirano $\mathrm{et} \mathrm{al}^{8}{ }^{8}$ reported a pressure rise of more than $7 \mathrm{mmHg}$ in $15 \%$ of eyes with bag-fixated lenses and $23 \%$ with sulcus-fixated lenses. These differences by univariate tests were not significant. They did find a strong association between IOP rise and anterior chamber particles and flare, which were quantitated by a laser flare-cell meter. The anterior chamber reaction peaked at 3 hours.

The IOL provides a barrier to capsular debris after laser capsulotomy ${ }^{3}$ and it has been suggested that bag-fixated IOLs provide a more effective barrier than sulcus-fixated IOLs to debris entering the anterior chamber and blocking the trabecular meshwork. $^{4}$ Eyes with a sulcus-fixated lens show a significantly greater breakdown of the blood-aqueous barrier than do capsular bag-fixated lenses. 'Posterior iris chafing' syndromes with pigment dispersion due to cells released by contact between the sulcus-fixated angulated loops and the back of the iris have been reported. ${ }^{9-11}$ Histological examination of these eyes demonstrates anterior chamber angle pigment deposition. ${ }^{10}$ It is possible that these 
eyes have a decreased outflow facility and would suffer a pressure rise when faced with large amounts of capsular debris after a laser capsulotomy.

There was no significant difference in the maximum pressure rise between glaucomatous and nonglaucomatous eyes in this study. Previous studies show conflicting results. ${ }^{1,2,5}$ However, in our study the bag-fixated eyes in the glaucoma group showed no pressure spikes while $43 \%$ of the haptic in/out eyes and $60 \%$ of the sulcus-fixated eyes of this group showed a pressure rise of more than $5 \mathrm{mmHg}$. This suggests that even in glaucomatous eyes IOL fixation is an important determinant of post-YAG laser IOP rise. The mechanism is likely to be a decreased outflow facility. ${ }^{1,2}$

A high proportion of eyes with sulcus-fixated lenses had anterior chamber cells and capsular debris. Laser-induced shock waves may be transmitted via the loops to the vascular uvea, disrupting the bloodaqueous barrier in these eyes. The shock waves could also induce frictional movement between the loops and the posterior iris, thus adding to the inflammatory debris. In the eyes with capsular bag-fixated lenses it is possible that the laser shock waves are dampened by distribution of the energy throughout the zonules. ${ }^{4}$ Furthermore, the loops of bag-fixated lenses are prevented from contact with the posterior iris by the anterior capsule. The reaction to laser in eyes with one haptic in the bag and the other in the sulcus would probably depend on the extent of contact between the loop and the extent to which it was in the bag, i.e. the percentage of its circumference enveloped by the anterior capsule. In this study a significant correlation was found in the haptic in/out group between the IOP rise in the first 2 hours after capsulotomy and the extent to which the IOL was enclosed by the anterior capsule.

Prophylactic use of topical apraclonidine has been advocated to prevent an acute IOP rise after Nd:YAG laser capsulotomy. ${ }^{13,14}$ Silverstone et al. ${ }^{13}$ showed that the use of topical $1 \%$ apraclonidine before capsulotomy resulted in a lower incidence of acute IOP rise than in the control group. They did not investigate IOL fixation. However, 7\% (11 eyes) of the treated eyes did have an acute IOP rise and there were also a few treatment-related adverse effects. The routine use of prophylactic apraclonidine might lull the clinician into a false sense of security, as is borne out by a case report on delayed pressure rise after Nd:YAG capsulotomy despite pretreatment with apraclonidine. ${ }^{14}$ If fixation in the bag is ensured it may not be necessary to use prophylactic treatment.

A recent study by Smith et al. on the barrier function of the posterior capsule after $\mathrm{Nd}$ :YAG capsulotomy concluded that anterior vitreous disruption and the absence of a posterior chamber lens, but not the size of capsulotomy, were related to the loss of barrier efficiency. ${ }^{15}$ The variations of lens fixation were not investigated. The conclusion of the present study is complementary to that of Smith et al., i.e. optimisation of all components of the extracapsular barrier complex, whether at the initial surgery and posterior chamber lens placement or at later laser capsulotomy, is protective and desirable.

Key words: Capsular bag, Ciliary sulcus, Intraocular lens, Intraocular pressure, Neodymium-YAG laser, Posterior capsulotomy.

\section{REFERENCES}

1. Richter CU, Arzeno G, Pappas HR, Steinart RF. Intraocular pressure elevation following Nd:YAG laser posterior capsulotomy. Ophthalmology 1985;92:63640.

2. Channell MM, Beckman H. Intraocular pressure changes after neodymium-YAG laser posterior capsulotomy. Arch Ophthalmol 1984;102:1024-6.

3. Kraff MC, Sanders DR, Lieberman HL. Intraocular pressure and the corneal endothelium after neodymium-YAG laser posterior capsulotomy. Arch Ophthalmol 1985;103:511-4.

4. Gimbel HV, Van Westenbrugge JA, Sanders DR, Raanan MG. Effect of sulcus vs capsular fixation following posterior capsulotomy. Arch Ophthalmol 1990;108:1126-9.

5. Slomovic AR, Parrish RK. Acute elevations of intraocular pressure following Nd:YAG laser posterior capsulotomy. Ophthalmology 1985;92:973-6.

6. Gimbel HV, Neuhann T. Development, advantages and methods of the continuous circular capsulorhexis technique. J Cataract Refract Surg 1990;16:31-7.

7. Tan DTH, Chee SP. Early central posterior capsular fibrosis in sulcus-fixated biconvex intraocular lenses. J Cataract Refract Surg 1993;19:471-80.

8. Altamirano D, Mermoud A, Pittet N, Melle GV. Aqueous humor analysis after Nd:YAG capsulotomy with a laser flare-cell meter. J Cataract Refract Surg 1992;18:554-8.

9. Masket S. Pseudophakic posterior iris chafing syndrome. J Cataract Refract Surg 1986;12:252-6.

10. Apple DJ, Reidy JJ, Mamalis N, Novak LC. A comparison of ciliary sulcus and capsular bag fixation of posterior chamber intraocular lenses. Am Intra-ocul Implant Society 1985;11:44-63.

11. Pignalosa B, Toni F, Ligouri G. Pigmentary dispersion syndrome subsequent to IOL implantation in PC. Doc Ophthalmol 1989;73:231-4.

12. Pollack IP, Brown RH, Crandall AS, Robin AL. Prevention of rise in intraocular pressure following neodymium-YAG posterior capsulotomy using topical 1\% apraclonidine. Arch Ophthalmol 1988;106:754-7.

13. Silverstone DE, Brint SF, Olander KW, Taylor RB. Prophylactic use of apraclonidine for intraocular pressure increase after Nd:YAG capsulotomies. Am J Ophthalmol 1992;113:401-5.

14. Nesher R, Kolker AE. Delayed increased intraocular pressure after Nd:YAG laser posterior capsulotomy in a patient treated with apraclonidine. Am J Ophthalmol 1990;110:94-5.

15. Smith TR, Moscoso WE, Trokel S, Auran J. The barrier function in neodymium-YAG laser capsulotomy. Arch Ophthalmol 1995;113:645-52. 